\title{
Non-progressive cerebellar ataxia, aplasia of pupillary zone of iris, and mental subnormality (Gillespie's syndrome) affecting 3 members of a non-consanguineous family in 2 generations
}

\author{
M. d'A. CRAWFURD, ${ }^{1}$ R. B. HARCOURT, AND P. A. SHAW ${ }^{2}$ \\ From the Department of Genetics, University of Leeds ${ }^{1}$; and the Ophthalmic Department, Leeds \\ General Infirmary, ${ }^{2}$ Leeds
}

SUMMARY A family is reported in which a brother and sister both showed non-progressive cerebellar ataxia, aplasia of the pupillary zone of the iris, and mild mental subnormality. These clinical findings were similar to those in two previous case reports. Despite the birth of an affected son to the affected sister, this family is considered to confirm autosomal recessive inheritance of this syndrome. The paternity of the mother's husband is supported by blood groups and biochemical markers and it is presumed that the husband is a heterozygote, even though no consanguinity could be detected.

The hereditary ataxias are an ill-defined group of disorders of which the best known is Friedreich's ataxia. Many other syndromes have been described, some of which are clearly defined entities, but others are of uncertain clinical, pathological, and genetic status. The clear delineation of further specific disorders is helpful in the classification of this group and is of practical use in genetic counselling.

Gillespie (1965) first reported the combination of partial aniridia, cerebellar ataxia, and mental subnormality affecting a brother and sister. Sarsfield (1971) described a sporadic case of a boy similarly

${ }^{1}$ Present address: Division of Inherited Metabolic Diseases, MRC Clinical Research Centre, Watford Road, Harrow, Middlesex HA1 3UJ.

${ }^{2}$ Present address: Consultant Ophthalmic Surgeon, City General Hospital, Stoke-on-Trent, Staffs.

Received for publication 29 December 1978. affected. We report here a further family of a young man, his elder sister, and her son, all with the same association of abnormalities (Fig. 1).

\section{Case reports}

CASE 1 (III.8)

This Caucasian female, the first of three sibs, was born at term in 1955. She was delivered at home after a prolonged labour of about 36 hours and weighed $3300 \mathrm{~g}$. In the first few months of life she suffered unexplained episodes of vomiting and had difficulty with feeding. The parents also noticed a tremor of the hands and feet from early infancy and she was late in passing most of her milestones. She first sat at 15 months, stood at 20 months, and first spoke at 2 years; there was also some delay in walking and she was backward in her social behaviour. At the

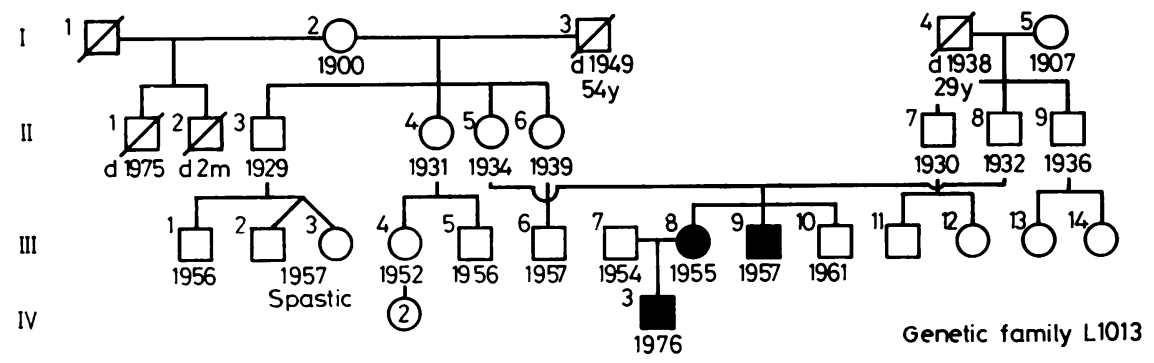

Fig. 1 Pedigree of family. 
age of 3 years 3 months the child was more fully assessed and was found then to weigh $13.15 \mathrm{~kg}$ and was $92 \mathrm{~cm}$ in height. She had a gross intention tremor of all limbs, gross ataxia of gait with high stepping, and required support while walking. There was hyperreflexia of the legs and extensor plantar responses, although tone was normal. Sensation was normal and a moderate degree of mental subnormality was noted.

Ophthalmic examination showed that there was jerky nystagmus on full right and left lateral gaze, but no squint was present and the range of ocular: movements was full. The pupils were very large and: showed no reaction to light or to accommodation? The marginal portion of the iris from the collarette to the pupillary border was completely absent in bot席. eyes (Fig. 2). The remaining portion of the iris was hypoplastic and poorly pigmented with an absence of crypts, and there were a large number of strandsis similar to persistent pupillary membrane strands $\vec{\odot}$ inserted from the collarette into the anterior lenscapsule of both eyes (Fig. 3, 4). There was nळ्.

Fig. 2 Case 1 showing large unreacting pupils.
Fig. 3 and 4 Case 1. Right and left eyes showing persistent pupillary membrane strands.

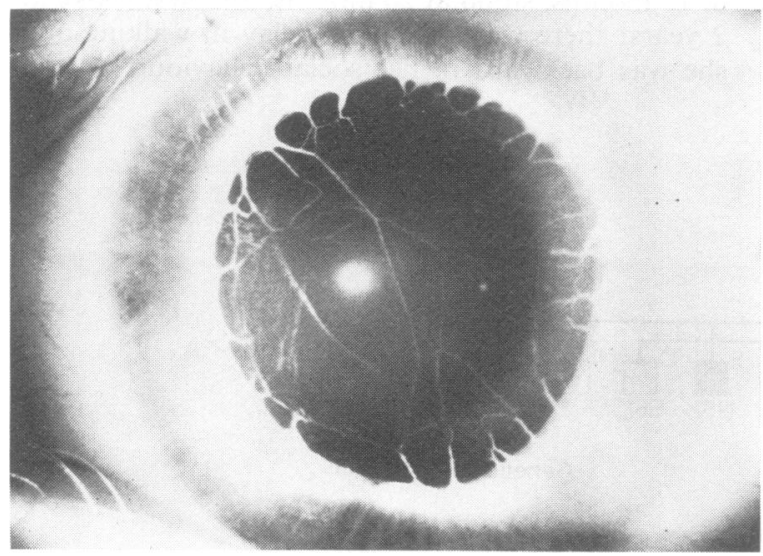

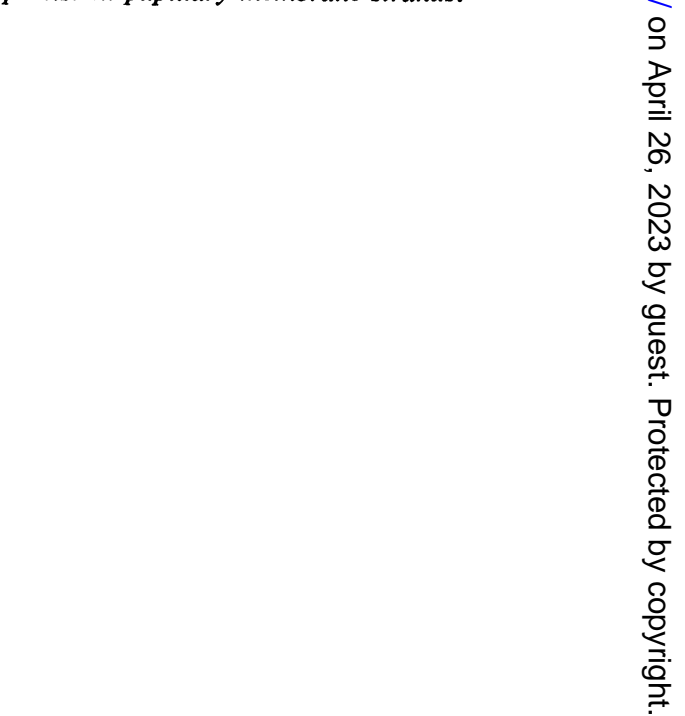


abnormality in the ocular media, and in particular the lenses were clear and the optic discs were of normal appearance. All laboratory investigations were normal.

The ataxia has shown no progression and vision and hearing have remained normal. Persistent mild mental retardation resulted in the girl attending a school for handicapped children up to the age of 16 years. During this period her locomotion improved considerably with physiotherapy and she has been able to get about satisfactorily without a walking aid. Since leaving school she has worked as a hand painter and as a packer.

The patient was seen again at the age of 19 years for genetic counselling as she was intending to marry. At that time there was no change in her ocular state and her visual acuity was $6 / 6$ in both eyes with correction of a moderate degree of hypermetropic astigmatism. The pupils did not constrict at all after instillation of pilocarpine $2 \%$ eyedrops. A moderate degree of accommodative function was present. The intraocular pressures were within normal limits on repeated applanation tonometry. There had been no progression in the ataxia; the patient showed slight incoordination of her hands and was unable to walk heel to toe. Psychological testing was carried out using the standard progressive matrices test of general intellectual ability and the Mill Hill Vocabulary Scale which indicated educational attainment with the following results. (1) Matrices, grade IV, 7 th centile. This is classified as definitely below average but above the defective level. (2) Vocabulary, grade IV, 25th centile. This is also definitely below average but higher than the Matrices score.

\section{CASE 2 (III.9)}

This boy was born on 17.1.58; he was the younger brother of case 1 and the second of three sibs, the third being a normal boy. There was a history from the age of 5 months of 'fits' characterised by head nodding, frequent blinking, and upward deviation of both eyes for periods of 3 to 4 minutes, and these have occurred on at least nine occasions.

His parents noticed a tremor of the hands and feet and incoordination from infancy. He has had unsteadiness of gait and clumsiness of hands all his life. Although this incoordination has been present to a more marked degree than in his sister, necessitating the use of a stick when walking, it has not progressed.

The child was slow in reaching his milestones and was reported as being unable to sit unaided at 14 months, unable to crawl or stand at 21 months, and he did not walk before the age of 3 years. He was found to be mildly subnormal and dysarthric with a high arched palate, small scapulae, drooping shoulders, and flat feet. Movement in the arms was very incoordinated and the gait very unsteady. The tone in the legs was diminished, but the reflexes and plantar responses were normal.

A thorough ophthalmic examination for genetic counselling purposes was carried out at the age of 17 years and the ocular features were found to be similar to those affecting his elder sister (Fig. 5).

\section{CASE 3 (IV.3)}

The sister, case 1, married in 1975 and gave birth to a son the next year. On examination at birth he was found to have eye signs similar to those of his mother (Fig. 6, 7), but no congenital neurological abnormality. By the age of 12 weeks he was already showing delay in head control and by 5 months this was marked and he showed extreme hypotonia and delay in social responsiveness. At $8 \frac{1}{2}$ months, after 3 months of physiotherapy, his head control had improved and he could roll. He could also reach out for objects, but on doing so showed ataxia. At the age of 18 months his motor development was at a

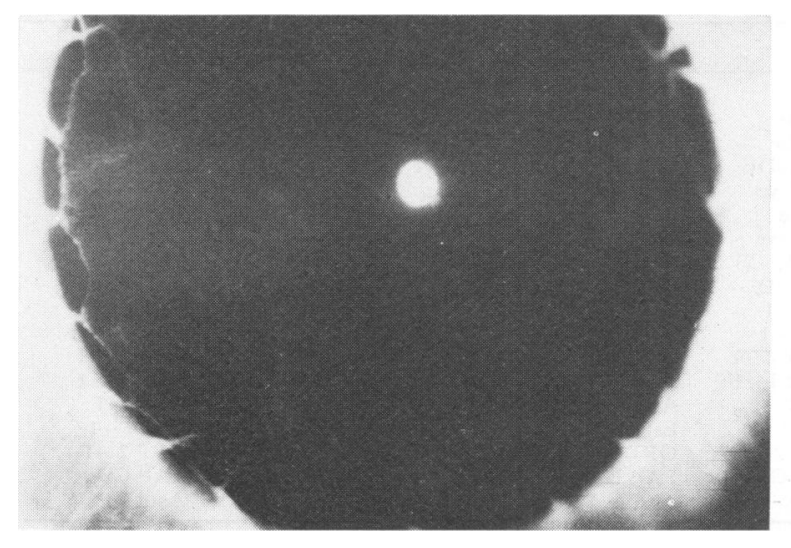

Fig. 5 Case 2. Right eye showing pupillary abnormalities similar to case 1. 


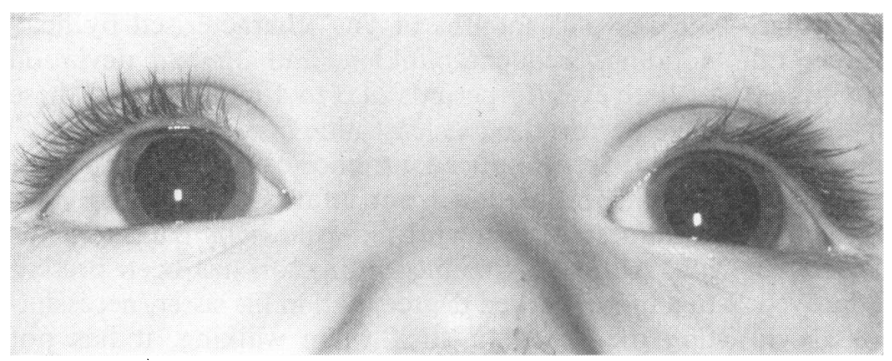

Fig. 6 Case 3 showing large unreacting pupils similar to cases 1 and 2.

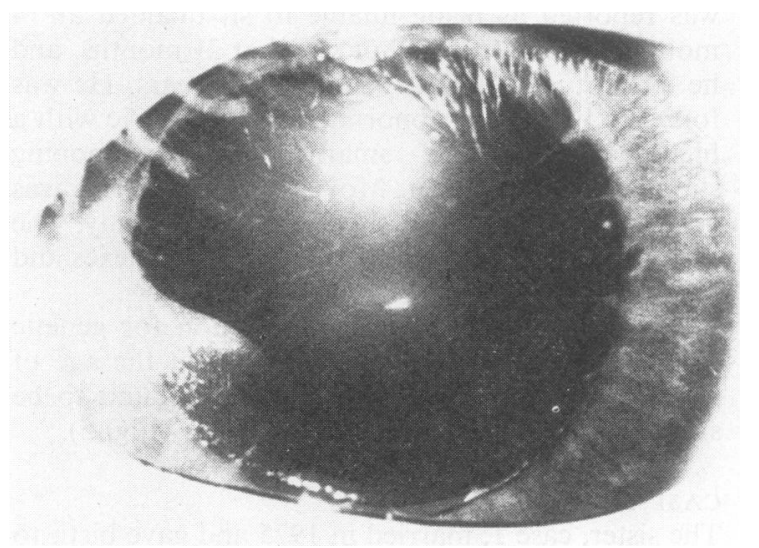

Fig. 7 Case 3. Close-up of right anterior segment showing similar pupillary abnormalities.

7-month level. He was very hypotonic and his tendon reflexes were difficult to elicit. He could pull himself along and sit alone but was unstable and could stand unaided for only very short periods. His ataxia was apparent on purposive movements such as clapping. His social and verbal development appeared to be in advance of his motor development and were then at about the 10-month level.

\section{Family history}

The family pedigree is shown in Fig. 1. The parents of cases 1 and 2 (II.5 and II.8) are both well and the mother has been examined and shows no sign of the disorder. The younger brother shows no abnormalit产 apart from a fine circular imprint on the posteriof capsule of the right lens. The husband (III.7)

Table Blood grouping

\begin{tabular}{|c|c|c|c|c|c|c|c|}
\hline Blood group system & II.5 & II.8 & III.7 & III.8 & III.9 & III.10 & $I V .3$ \\
\hline ABO & O & $A_{1}$ & O & O & $\mathbf{A}_{1}$ & $\mathbf{A}_{1}$ & O \\
\hline MNSs & NSs & MSs & MNSs & MNSs & MNSs & MNSs & NSs \\
\hline Rhesus & CCDee & CcDee & CcDEe & CcDee & CCDee & CCDee & ccDEe \\
\hline Probable genotype & $\mathrm{Cde} / \mathrm{CDe}$ & $\mathrm{CDe} / \mathrm{cde}$ & $\mathrm{CDe} / \mathrm{cDE}$ & $\mathrm{CDe} / \mathrm{cde}$ & $\mathrm{CDe} / \mathrm{CDe}$ & $\mathrm{CDe} / \mathrm{CDe}$ & cDE/cde \\
\hline Duffy & Fya + ve & Fya + ve & Fya + ve & Fya - ve & Fya + ve & Fya-ve & Fya - ve \\
\hline Kell & $\mathbf{K}-\mathrm{ve}$ & $\mathbf{K}-\mathrm{ve}$ & $\mathbf{K}-\mathrm{ve}$ & $\mathrm{K}-\mathrm{ve}$ & K-ve & $\mathbf{K}-\mathbf{v e}$ & $\mathrm{K}-\mathrm{ve}$ \\
\hline Lutheran & Lua - ve & Lua - ve & Lua - ve & Lua - ve & Lua - ve & Lua - ve & Lua - ve \\
\hline Inv & $\operatorname{Inv}(-1)$ & $\operatorname{Inv}(-1)$ & $\operatorname{Inv}(-1)$ & $\operatorname{Inv}(-1)$ & $\operatorname{Inv}(-1)$ & $\operatorname{Inv}(-1)$ & $\operatorname{Inv}(-1)$ \\
\hline Haptoglobins & $\mathrm{Hp} 2-2$ & $\mathrm{Hp} 2-2$ & Hp 1 - 1 & $\mathrm{Hp} 2-2$ & $\mathrm{Hp} 2-2$ & $\mathrm{Hp} 2-2$ & Hp2-1 \\
\hline Gc & Gc $1-1$ & Gc $2-1$ & Gc $1-1$ & Gc $1-1$ & Gc $1-1$ & Gc $2-1$ & Gc $1-1$ \\
\hline PGM & PGM 1-1 & PGM 1-1 & PGM 2-1 & PGM 1-1 & PGM 1-1 & PGM 1-1 & PGM 2-1 \\
\hline ADA & ADA $1-1$ & ADA $1-1$ & ADA $1-1$ & ADA 1-1 & ADA $1-1$ & ADA $1-1$ & ADA 1-1 \\
\hline AK & AK $1-1$ & AK $1-1$ & AK $1-1$ & AK $1-1$ & AK 1-1 & AK 1-1 & AK $1-1$ \\
\hline EsD & EsD 1-1 & EsD 1-1 & EsD 1-1 & EsD 1-1 & EsD 1-1 & EsD $1-1$ & EsD $1-1$ \\
\hline GPT & GPT 2-1 & GPT $2-1$ & GPT 2-1 & GPT $2-1$ & GPT 2-2 & GPT $2-2$ & GPT $2-1$ \\
\hline EAP & EAP BA & EAP B & EAP CB & EAP B & EAP BA & EAP B & EAP CB \\
\hline
\end{tabular}


case 1 is a healthy 24-year-old man. It was not possible to trace any connection between his own family and that of his wife. Her parents are not consanguineous as far as is known, although three of her grandparents came from Bradford and her husband's family also comes from the Leeds/ Bradford conurbation. Fresh inquiry into the family reported by Sarsfield (1971), who came from Doncaster, about $\mathbf{4 0}$ miles from Bradford, failed to show any connection with the families of III.7 or III.8. The results of blood group studies on the family are given in the Table.

\section{Discussion}

The affected subjects described here have features of cerebellar ataxia and bilateral aplasia of the pupillary zone of the iris similar to those affecting the patients reported by Gillespie (1965) and by Sarsfield (1971). In addition, they are all mildly mentally retarded as was Sarsfield's patient. Despite the fact that Gillespie's two sibs were, judging from his description, more severely mentally retarded, it seems reasonable to regard all five patients as having a similar disease. It is also important to emphasise the fact that there was no progression of the cerebellar ataxia in childhood in any case, and indeed some slight improvement has been effected by physiotherapy.

The finding of this third family, with a triad of features first described by Gillespie, clearly distinguishes this disorder from other forms of hereditary cerebellar ataxia associated with ocular defects. Thus, it is distinct from the Marinesco-Sjögren syndrome which is characterised by cerebellar ataxia, congenital cataracts, and mental subnormality (Marinesco et al., 1931; Andersen, 1965); from the infantile cerebellar ataxia with progressive external ophthalmoplegia (Franceschetti et al., 1945); from Behr's syndrome of optic atrophy with pyramidal and cerebellar dysfunction (Behr, 1909; Franceschetti and Bamatter, 1940); and from spinocerebellar ataxia with pupillary paralysis (Indemini and Amman, 1961; Sutherland et al., 1963) in which the pupillary light reflexes are absent, but the pupillary accommodation responses are maintained. Congenital non-progressive cerebellar ataxia associated with mental retardation and retinal colobomata has also been described, following an autosomal recessive pattern of inheritance (Pfeiffer et al., 1974). In Refsum's syndrome, the hereditary cerebellar ataxia is associated with chronic hypertrophic polyneuritis and atypical progressive pigmentary degeneration of the retina leading to blindness (Refsum, 1946). The disorder is transmitted as an autosomal recessive trait and is the result of an inborn error of lipid metabolism, the absence of the enzyme phytanic acid $\alpha$-hydroxylase. Somewhere between this metabolic disorder and the structural abnormalities of the Gillespie and MarinescoSjögren syndromes lies Friedreich's ataxia, in which nystagmus is present in about half the cases, optic atrophy occasionally occurs, and ptosis, abnormalities of pupillary reflexes, and ophthalmoplegia are a rarity.

The defect in the structure of the iris in the present disorder must be distinguished from hereditary aniridia in which there is an almost total absence of the iris tissue, apart from a small frill of tissue on the anterior surface of the ciliary body. Aniridia is inherited as an autosomal dominant trait, or occurs as a fresh mutation (Shaw et al., 1960), and often leads to the development of secondary glaucoma. In a few cases the disorder has been associated with Wilm's tumour and with hemihypertrophy (Miller et al., 1964).

The finding of two families with affected sibs and one sporadic case strongly suggests autosomal recessive inheritance even in the absence of parental consanguinity in any of the three families. The unexpected birth of an affected son to one of the two affected sibs reported here, contrary to the genetic advice given to the mother, does not alter the presumption of autosomal recessive inheritance. The pedigree cannot be interpreted as showing sex linked inheritance; it could only be interpreted as showing autosomal dominant inheritance on the assumption of a failure of penetrance in one or other parent, and that the disorder in this family is the result of a different gene from that in the other two reported families. The blood groups listed in the Table are compatible with the parentage shown in Fig. 1 for III.8-10 and IV.3, and exclude an incestuous paternity of IV.3 of his maternal grandfather or either of his maternal uncles. Furthermore, II.7 and II.9 and their families live in Australia.

As only 1 in 250 men among Western Europeans have the blood group combination that IV.3 must have inherited from his father, it is most unlikely that the father is not III.7. The most likely explanation of this remarkable family history is that the disease present is indeed inherited in an autosomal recessive manner and that the father (III.7) is a heterozygote as a result of some remote, undetected consanguinity. Owing to the geographical propinquity of Sarsfield's family, there may well also be an undetected connection between his family and that reported here.

It is suggested that for the purpose of genetic counselling this disorder should provisionally be regarded as autosomal recessive with a 1 in 4 risk of sibs of affected patients being affected. 
We are grateful to Dr Alan Grant, Senior Lecturer in Forensic Serology, Guy's Hospital, London for his detailed blood grouping reports. We also thank Dr G. T. Leelman, Consultant Paediatrician, Bradford Children's Hospital for his reports regarding the general progress of case 3, and Dr Michael Baraitser, Consultant Clinical Geneticist, Kennedy Galton Centre, for helpful comments on the manuscript.

\section{References}

Andersen, B. (1965). Marinesco-Sjogren syndrome: spinecerebellar ataxia, congenital cataract, somatic and mental retardation. Developmental Medicine and Child Neurology, 7, 249-257.

Behr, C. (1909). Die komplizierte, hereditär-familiäre Optikusatrophie des Kindesalters; ein bisher nicht beschriebener Symptomkomplex. Klinische Monätsblatter für Augenheilkunde, 47, (ii), 138-160.

Franceschetti, A., and Bamatter, F. (1940). Atrophie optique infantile associée à des troubles generaux (syndrome de Behr). Schweizerische Medizinische Wochenschrift, 21 , 285-286.

Franceschetti, A., de Morsier, G., and Klein, D. (1945). Über eine neue mit Ophthalmoplegia externa progressiva kombinierte infantile form von zerebellarer Heredotaxie (P. Marie) bei vier Geschwistern. Archiv der Julius KlausStiftung für Vererbungsforschung, Sozialanthropologie und Rassenhygiene, 20, (Suppl.), 59-81.
Gillespie, F. D. (1965). Aniridia, cerebellar ataxia and oligo phrenia in siblings. Archives of Ophthalmology, 73, 338-341?:

Indemini, M., and Ammann, F. (1961). Hérédo-dégénéres cence spino-cérébelleuse (HDSC) associée au syndrome dêt Klinefelter. Journal de Génétique Humaine, 10, 297-235. 음

Marinesco, G., Draganesco, S., and Vasiliu, D. (1931)므 Nouvelle maladie familiale caracterisée par une cataracte congénitale et un arrêt du développement somato-neuro psychique. Encéphale, 26, 97-109.

Miller, R. W., Fraumeni, J. F., and Manning, M. D. (1964)ף Association of Wilm's tumor with aniridia, hemihyper-trophy and other congenital malformations. New England Journal of Medicine, 270, 922-927.

Pfeiffer, R. A., Palm, D., Jünemann, G., Mandl-Kramer, S. $\vec{\omega}$ and Heimann, E. (1974). Nosology of congenital nong progressive cerebellar ataxia. Neuropädiatrie, 5, 91-102.

Refsum, S. (1946). Heredopathia atactica polyneuritiformiṣ̂ Acta Psychiatrica et Neurologica, Suppl. 38, 1-303.

Sarsfield, J. K. (1971). The syndrome of congenital cerebella or ataxia, aniridia and mental retardation. Developmentad, Medicine and Child Neurology, 13, 508-511.

Shaw, M. W., Falls, H. F., and Neel, J. V. (1960). Congenitaf anirida. American Journal of Human Genetics, 12, 389-41 5

Sutherland, J. M., Tyrer, J. H., and Eadie, M. J. (1963)Atrophie spino-cérébelleuse familiale avec mydriase fixe Révue Neurologique, 108, 439-442.

Requests for reprints to Dr M. d'A. Crawfurd, Division of Inherited Metabolic Diseases, Clinicado Research Centre, Watford Road, Harrow, Middlesexô HA1 3UJ. 